Open Access

\title{
Understanding middle class consumers from the justification of taste: a case study of Beijing
}

Di Zhu

\author{
Correspondence: zhudisoc@163.com; \\ zhudi123@cass.org.cn \\ Institute of Sociology, Chinese \\ Academy of Social Sciences, No. 5 \\ Jian Guo Men Nei Da Jie, Dong \\ Cheng District, Beijing 100732, \\ China
}

\begin{abstract}
This paper focuses on the consumer orientation of the middle class in contemporary China, using the data from 30 interviews with middle class people conducted in Beijing. The existing literature tends to depict the Chinese middle class one-dimensionally as in pursuit of either conspicuous display or frugality and neglect the moral justifications consumers deploy, whereas this paper argues that peoples' justifications for their tastes are key to understanding contemporary Chinese consumers. My analysis draws attention to both aesthetic and moral justifications of taste present in subjective accounts. It highlights consumers' self-referential orientations: the pursuit of pleasure, tempered by considerations regarding comfort, is a major form of aesthetic justification. Living within one's means, i.e. keeping a balance between expenditure and income, is the main moral justification of taste of the middle class. Consumers' orientations draw on a new set of elements, conceptualised in this research as 'the orientation toward personal pleasure and comfort'. Although having been common and widespread in most highly developed capitalist economies, these elements did not exist in Maoist China. Nevertheless, this orientation, combined with motives and orientations already present in China, can be seen to have taken effect from the way people justify their patterns of consumption in the course of interviews.

Keywords: Taste, Justification, China, Middle class, Consumption
\end{abstract}

\section{Introduction}

Until 1978, the hegemonic discourse in China demanded the ethic of frugality, and saving for the future has remained as a feature of Chinese people to the present day (Chua 2000). The traditional Chinese culture advocates sacrifice and commitments, for example, for family and work. However, many scholars argue that in the contemporary period, especially after 1978, Chinese have become more engaged in conspicuous consumption and extravagant expenditure (Chen 2003; Wang 2005). Such a paradoxical picture-a pattern of conspicuous consumption embedded in a less developed, frugal, and even ascetic national and cultural context-has left the consumer orientation of Chinese people something of a mystery. The contradiction is significantly exhibited by the contemporary middle class, who participate in consumption practices more extensively, enabled by their increasing economic and cultural capital. This paper aims to untangle the mystery by revealing ways in which the consumer orientation of the

(C) 2016 The Author(s). Open Access This article is distributed under the terms of the Creative Commons Attribution 4.0 International License (http://creativecommons.org/licenses/by/4.0/), which permits unrestricted use, distribution, and reproduction in any medium, provided you give appropriate credit to the original author(s) and the source, provide a link to the Creative Commons license, and indicate if changes were made. 
middle class has developed and how new elements in consumer orientation are tempered by a more traditional set of motives. The guiding research questions are as follows: What justifications of consumption are offered by the Chinese middle class? And which type of consumer orientation is implied by those answers? This paper will address them mainly through an examination of taste, namely the preferences expressed in consumption.

While consumption patterns of the contemporary middle class have been widely studied by scholars of various social science disciplines, the existing studies either are descriptive analyses with less theoretical concerns or build their arguments upon ambiguous links with empirical evidence. There are hence no fully satisfactory explanations of patterns of consumption, and, in particular, how people orient themselves toward goods and services in China.

Among many of the relevant studies, Zhou Xiaohong, Wang Jianping and Wang Ning have made important contributions to sociological understandings of middle class consumers. Based on empirical evidence, Zhou and Wang both agree that the middle class are ambivalent with either frugality or consumerism and strive to balance them. As regards the proposition 'it is necessary to spend the money due in future', $43 \%$ of middle class respondents think it appropriate, whereas the corresponding percentage is much lower among lower class respondents (29 \%) (Zhou 2005, 73). It is explained that this difference is enabled by the steady jobs and income among the middle class (ibid: 73). Moreover, $61 \%$ of middle class respondents think the statement appropriate that 'it is wiser to earn and spend than to be frugal and save', yet only $44 \%$ of lower class respondents think so (ibid: 74$)$. Wang $(2007,136)$ is more emphatic by arguing that the consumer orientation of the middle class is in a tremendous transition, from traditional frugality to modern consumerism. Wang (2006) summarises the tensions that have shaped the consumption patterns of the middle class in such a transitional society: between (1) extravagance and frugality, (2) passion and rationality, (3) sovereignty and passiveness, (4) high culture and popular culture, and (5) self-identity and social identity. These arguments on consumer orientation help to construct a theoretical framework to analyse the consumer culture in China. However, they are not elaborated sufficiently. For instance, questions such as how the new values are tempered by traditional values, what the relations are between the tensions, and how the middle class cope with the tensions need to be resolved. Wang Ning $(2007 ; 2012)$ further examines mechanisms and consequences of the new consumption patterns from an institutionalism paradigm. He argues that the state plays a key role in stimulating people's material aspiration for the purpose of economic development. Due to a productionist institutional setting, however, consumers have been directed to overspending rather than the real improvement of their life quality.

These studies illustrate the context in which the contemporary middle class is situated. The policy of consumption stimulation should be partly responsible for the conspicuous and excessive consumption in contemporary China. However, rationing and management of material goods by the state is no longer the prior structure of the consumer market. Consumers have become more autonomous and the justification of taste' is required: they cannot always feel confident in their taste if they lack a class identity or culture as a reference. However, a common problem in many of the existing studies is the taken-for-granted influence of the Western culture ${ }^{1}$ and the attribution of 
the new consumer orientation to 'consumerism'. It would be arbitrary to regard the new set of consumer orientation in China as imported or diffused from the West. In addition, there is no empirical evidence showing that the new motives and orientations are homogenous with 'consumerism' or 'hedonism', both having originated and developed in the West.

This paper will provide a comprehensive analysis of the underlying consumer orientation: what is it and how does it work? 'Consumer orientation' here refers to distinct or particular rationales and motives for purchasing and using certain material goods and services. Through an examination of middle class interviewees' justifications of their own tastes, this paper will reveal their consumer orientation. The following section will explain why people's justifications of their tastes are important for understanding this consumer orientation.

\section{The justification of taste and self-referential orientations}

Taste is the clue to understand people's consumption patterns in the large body of literature in the sociology of consumption, from the early humanist tradition which considers taste as self-evident, to the contemporary Bourdieusian explanation of symbolic power. 'The justification of taste' is an element central to the theory of taste, which seeks to delineate the relationship between taste and social distinction (Warde 2008). The justification of taste evolves from the performance of making judgements upon taste and concerns how judgements of others' tastes create social divisions that serve power and privilege. Through justifications, people can feel good about their tastes and be confident in them. The justification of taste is a mechanism neglected by Bourdieu who sees taste as arising from habitus, but it is important in contemporary society. In light of social changes brought by advertising, marketing and media commentary, justifications of taste are in flux, and 'justifications of good taste are constantly advanced and disputed as people consider the views of others in the community, change their minds, develop their competences, talk about their activity, and justify their judgements' (Warde 2008: 330-31).

Furthermore, in relation to the particularities of the Chinese culture and its social transitions, justifications of taste play a more important role in today's Chinese society. Justifications have been 'absent' in the Chinese context while they constitute the foundation of social order in the West. In Western societies, social order rests on the acceptance of the boundary constraints on individual freedom, and the behaviour principles aim more or less at independent individuals (Redding 1993). By contrast, Chinese religions and cultures seek a dialectical, harmonized and even 'compromised' relationship between individual and society (Zheng 2005). In fact, as Redding (1993, 44) points out, the Chinese state is in essence the superfamily of the Chinese people; within this structure, the maintenance of order is founded on the moral prescriptions for relationships. Thus, the place of justification has, in the past, been occupied by these prescriptions in accordance with social roles.

However, as argued by Davis (2005), a significant social transition in China, which has arisen along with the emergence of consumer culture, is consumer sovereignty, a more reflective and critical response to market and political sovereignty. Indeed, consumers are empowered to choose freely and autonomously. While they cannot rely on social discipline or the authority when shopping or making decisions, they are 
required to justify their choices to themselves and the community (friends, family, strangers in the virtual world, etc.). If there is difficulty in justifying their consumption, it might cause ambivalence or anxieties. Therefore, the status of justifications has significantly changed-once absent but now playing a key role in people's consumption practices.

The justification of taste is often derived from interpretations of how people understand their own consumption practices and reasons why they feel confident in their consumer choices. Based on the status of justification in everyday life, a more finegrained analysis of the justification of taste, together with the anxieties of consumption, can lead to better understanding of consumer orientation.

Another reason for the importance of the justification of taste lies in its methodological function as a 'corrective' to understand consumption practices from the view of actors. The existing literature often stresses 'conspicuous consumption' when studying Chinese middle class consumers. For example, a luxury gift is a way to display the ability to pay (Wong and Ahuvia 1998, 13). Symbolic value is attached to both luxurious and ordinary items when they are imported (Zhou and Hui 2003). 'Self-referential orientations', i.e. buying goods to satisfy personal physical and mental demands, have been ignored by many sociologists in the study of Chinese consumers. In this sense, Tsai's research (2005) is valuable in bringing attention to self-referential orientations, or in his terms, 'personal orientations', as opposed to the social goal of 'buying to impress others'. With cross-national empirical evidence, Tsai suggests that the motivation behind luxury-brand consumption also lies in self-directed pleasure, self-gift-giving, or congruity with an internal self, in addition to social salience and social identification. Self-referential orientations are also emphasised by Campbell $(1987,1995)$ who argues that the pleasure comes more from daydreaming and fantasy than from emulation and ostentation experienced in the real world. Campbell argues that the framework of 'pleasure-seeking consumers' or 'imaginative hedonism' might be the best way to understand modern consumption in general $(1995,118)$.

The reason that self-referential orientations are neglected lies in the fact that sociologists are keen to achieve a social understanding of consumption processes that values questions of class, status, inequality and social symbolism (as summarised by Woodward 2003). In order to tackle this problem, Woodward proposes a 'corrective' in his study of the middle class in Australia. Scholars could, he suggests, explore consumption from the viewpoint of actors, seeking to expose strategies, narratives and accounts that literally constitute the consumption act. Although subjective interpretations and justifications might be discursive, this paper tries to formulate a consistent system of justifications of taste and will show how the set of justifications can be used for understanding the consumer culture of contemporary China.

\section{Data collection methods}

The data used for this analysis are drawn from the 30 semi-structured interviews that I conducted in Beijing in 2008. As a metropolitan city, Beijing has attracted numerous middle class people and developed a flourishing consumer culture. These interviews explored shopping habits, dispositions toward material goods, preferences, material aspirations, anxieties and dilemmas, social interactions and metropolitan effects. 
This paper considers class, based on economic relations, as an important structure differentiating consumption practices, especially in developing countries. It is argued that social and material circumstances are closely associated with occupational experience, and the scales of occupational status may therefore be used to measure labour market outcomes associated with the system of production (Stewart et al. 1980). The measurement by salary alone, however, is unreliable because it represents neither employment relations nor cultural capital-the latter was emphasised by Bourdieu (1984) in conceptualising class. Rather, many Chinese scholars prefer a combined measurement based on occupation (Zhou 2005; Liu 2007; Li and Zhang 2008). This reflects the context of a transitional society where employment relations play a central role in terms of life chances, with education and lifestyles being less important in social stratification. This paper defines 'middle class' with occupational status and selected a sample of middle class subjects mainly on the basis of their occupation and power. Middle class occupations include business owners, managers, professionals and civil servants. No interviewee belongs to the social elites, so 'the middle class' in this research should be understood in the average sense, not particularly aiming at the elites or the lower-middle class. The social network of the author also facilitated the fieldwork. The majority of the interviewees were contacts of my friends and acquaintances. However, in order to avoid bias, I made an effort to contact people whom I had never met and cover as many varieties of middle class people as possible. Instead of achieving a representative sample like a random sampling survey would do, my purpose is to produce a set of systematic data from people with heterogeneous backgrounds with regard to age, gender, occupation, industry, hometown, education and income.

The interviewees are aged between 27 and 60, half of them are male. They work in various industries and institutions and are clustered around an annual income between 50,000 and 200,000 yuan. The distribution of income of the interviewees by age and gender can be visualised from Fig. 1. Gender difference in income is salient. More women are distributed at the bottom of the income pyramid between 50,000 and 200,000 yuan a year, while more men are positioned above the income of 200,000 yuan a year. Interviewees with an annual income below 200,000 yuan are mostly younger than 30 or above 50 and are working as civil servants, doctors in state-owned hospitals, lecturers or researchers, or professionals in companies early in their career. Four interviewees at the top of the income pyramid, which is 1,000,000 yuan a year and above, are two business owners in financial investment and art products, respectively, and two senior managers in a large-scale foreign company and a middle-scale media company.

\section{The aesthetic justification of taste}

When providing interpretations of their taste, the interviewees mainly discussed two dimensions of consumption that may help us understand the individuality and sociality of the individual: the dimension of the self (for example, personal interests and selfimprovement) and the social dimension (for example, commitments to others and the traditional ethic of frugality). This finding is consistent with what has been found in the empirical research by Woodward and Emmison (2001) who suggest that judgments of taste are not only a question of aesthetics - taste at the individual level, shaped by social and cultural power-but also matters of moral, ethical and communal sensibility. Building on this distinction, this paper terms the self dimension of justification 'aesthetic 


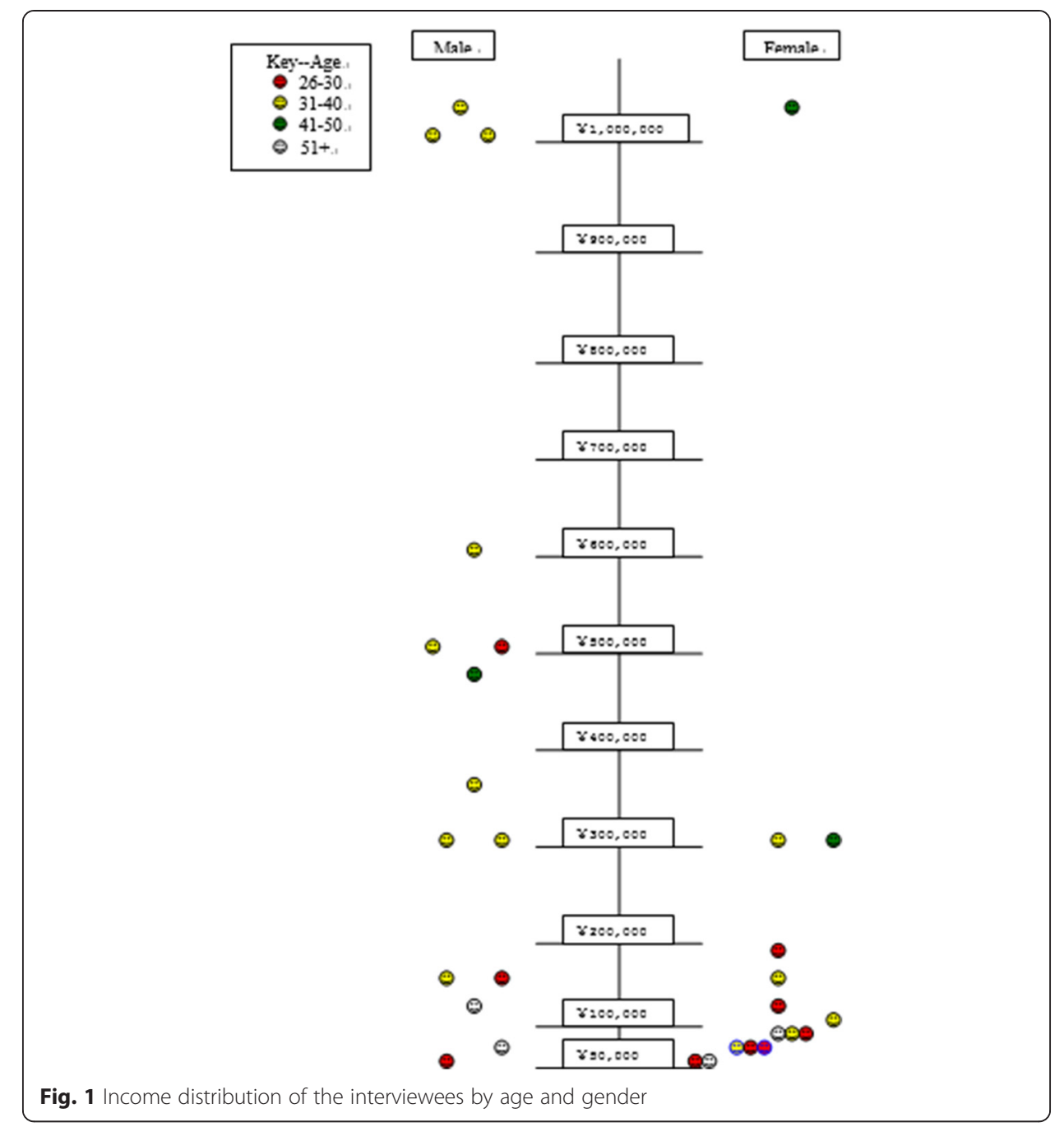

justification' (based on personal gratification) and the social dimension of justification 'moral justification' (the 'socialness' of taste, folding in questions of civility, collective sentiments and techniques of fashioning the self). The subsequent sections will analyse the justification of taste with regard to these two types of justification and examine tensions and associations between them.

Data on justifications are mainly generated from interviewees' interpretations of their own tastes. I firstly asked about their preferred material goods or services and their consumption priorities and then asked why they liked what they liked and how they would understand their own tastes. Although their preferred material goods or services vary, these interviewees generally emphasise pleasure, comfort, relaxation, self-rewards, status display and identity. They often responded to more than one of these motivations in their consumption patterns. Among the interviewees, the aesthetic of pleasure and the aesthetic of comfort (if relaxation can be understood as a form of comfort) stand out as the most significant.

Eight out of 30 interviewees explicitly used the terms 'pleasure, 'fun' or 'happy' when explaining why they preferred certain activities or material goods; for instance, 'They [digital products] bring pleasure to your life' and 'It [piano] makes my kids happy'. In addition, ten interviewees interpreted their tastes implicitly as pleasure seeking, such as 
aesthetic pleasure when going to galleries or engaging in tourism. Furthermore, no interviewees condemned the pursuit of pleasure in consumption. Among 18 interviewees with an orientation toward personal pleasure, many also pursue a comfortable life in using high-quality material goods or various services, such as eating out and shopping online. For example, they commented that 'I consider it [buying a car] an issue of convenience, related to improving quality of life' and that digital products 'bring convenience to life'. For ten other interviewees, comfort and the satisfaction of wants are the main motives of their consumption. Only two interviewees claimed that their main concern was status display or social identity, though these were also subsidiary motives for five other interviewees.

Thus, the interview data uncovered differentiated patterns of consumption in which pursuit of pleasure and comfort is the main form of aesthetic justification. No matter whether they were consuming for themselves, buying gifts for friends or going on holiday with family members, most interviewees were concerned with pleasure and comfort of oneself or other people, rather than an expressive motive like image management or wealth announcement. This paper differentiates 'self-referential orientations', implied in the pursuit of pleasure and comfort, from conspicuous consumption, implied in 'status display'. Next, this section will analyse self-referential orientations through a typology of gratification (see Table 1).

By studying eating-out practices in Britain, Warde and Martens (2000, 186) suggest that there are four realms of gratification: the sensual, the instrumental, the contemplative and the social. This framework is helpful in constructing systematic arguments on the aesthetic justification of taste and linking the justification agenda in the Chinese context with the Western context. According to the interview data, these four types of gratification are also found in the Chinese middle class. This typology of gratification, however, has some limitations when applied to a different national context. For instance, the boundary between each type of gratification may vary, and the implication and the balance between those types may be different. Care is therefore necessary when interpreting Chinese data within this analytic framework.

As interpreted by Warde and Martens (ibid: 186), pleasure and joy includes bodily pleasures, which Campbell (1987) associates with traditional hedonism. Sensual pleasures can be generally obtained by 18 interviewees who displayed an explicit or an implicit orientation to personal pleasure. It is very significant in the case of Flora who has collected a variety of perfumes and often uses them:

I like perfume because the bottle of perfume is normally beautiful, and I'm delighted to have a lovely fragrance. It puts me in a good mood to spray it on before leaving home ... just that kind of pleasure. (Flora, 27, female, migrant, consultant in a leading consulting $\mathrm{MNC}$ )

Table 1 Gratification: a typology

\begin{tabular}{lllll}
\hline Types of gratification & & & & \\
\hline & Sensual & Instrumental & Contemplative & Social \\
\hline Low intensity & Pleasure & Satisfaction & Entertainment & Participation \\
High intensity & Joy & Achievement & Appreciation & Mutuality \\
\hline
\end{tabular}

Source: Warde, A. and L. Martens (2000). Eating Out: Social Differentiation, Consumption and Pleasure, Cambridge: Cambridge University Press, p. 187 
Contemplative gratification includes experiences such as dreaming and fantasy, aesthetic appreciation and intellectual reflection, all of which offer rewards (Warde and Martens 2000, 186). Entertainment, the lower-intensity level of contemplative pleasure, is obtained by most of the interviewees through, for example, listening to music and watching films. However, intellectual appreciation-the higher level of contemplative pleasure-is limited to a few interviewees who showed extraordinary passion. For example, Frank and Flora-two young professionals-have developed their hobbies of using digital products and eating out to expert levels. The capacity to be a connoisseur is also a reflection of their greater cultural and economic capital.

Dreaming and fantasy play important roles in yielding contemplative gratification in the sense of constructing pleasure from even mundane activities. This skill is considered to be crucial in modern hedonism, which, as Campbell (1987) argues, is the underlying dynamic of the consumer culture in modern society. I will not generalise the theory of modern hedonism to the Chinese consumers in this research, nor will I attribute all practices of seeking pleasure from imagination to modern hedonism. However, my findings on contemplative gratification reveal new consumption patterns and point out important new forms of justification among interviewees. In their interpretations of their taste, some of them see pleasure, fun or stimulation as their objectives, although activities they use to create these feelings are different. These activities include drinking, going to clubs, shopping, taking holidays, and even cooking and driving which are not typical entertainment options. Other evidence of contemplative gratification can be found in window-shopping and self-guided tours. Three female interviewees (Diana, Wendy and Julia) expressed that they could gain pleasure from window-shopping, even though there was no real contact with the objects. As for self-guided tours, almost all of those seven interviewees who like travelling showed their preference to this mode of travel, although such tours consume more time and energy.

I like travelling by self-driving in China [...] I drove to Xinjiang, which is 12,000 kilometres for a round trip. You can never see some scenery if you are with a travel agent ... I stay for days if I see anything interesting ... there is no plan for my trips ... During the holiday, I'll follow my consistent aim that I must live in the best place and eat the best food (John, 40, male, migrant, chief procurement officer for China District in an MNC in chemicals)

These consumption practices allow more freedom to construct pleasure and therefore are more likely to generate a higher level of contemplative pleasure-appreciation. In particular, they create tension with subsequent release, which is thought to be a stronger stimulus leading to more persistent pleasure (Scitovsky 1976). John's quote also demonstrates multiple motivations of pursuing both pleasure and comfort in his consumption.

In the seeking of sensual and contemplative gratification, gender and age play a key role in differentiating the patterns. Among those interviewees who display a more significant orientation toward personal pleasure, most are men and young women. By contrast, the older female interviewees tend to stress comfort, relaxation or identity in consumption. A possible reason is that female interviewees are generally the main people in charge of household shopping, so they usually make their consumer decisions with regard to long-term family benefits. In contrast, men and young women in their 
twenties, with fewer household responsibilities, have more time to pursue pleasure, although they might aim at other goals as well.

Categories of instrumental and social gratification expand our understanding of pleasure by linking pleasure seeking with a wider range of social engagements. Instrumental gratification is connected to the world of achievement with regard to self-improvement and the monetary value of consumer goods, and social gratification stresses mutuality, reciprocity and sharing (Warde and Martens 2000, 186). Instrumental and social gratification are often neglected by scholars but are key elements of enjoyment in contemporary China where family commitments and work ethic are often emphasised.

Patrick's justification implies complicated consumer orientations. This 27-year-old professional with an annual income of about half a million yuan has a passion for luxury goods:

[Owning luxury goods] is pleasure for me. It makes you happy to own premium items of fine quality when one is rich. For example, a handbag from Hermes or Ferragamo or a watch from Blancpain, I think they're certainly worth the price, and they are gained by my hard work. If I could buy a big house now, it would be great pleasure to me (migrant, team leader in a leading IT multinational corporation)

Although Patrick indicates status display and identity claims, the underlying reason for Patrick's consumption is pleasure-both of the higher and lower levels of instrumental pleasure, especially a sense of achievement by hard work, and social pleasure by providing a comfortable life for his family. The implication is that consumption of luxury goods should not be merely understood as status display or social distinction, but rather, it might be tempered by the pursuit of pleasure and comfort.

An important source of social and instrumental gratification for the Chinese middle class is the commitment to children and parents. The young people who show a more significant orientation toward personal pleasure and comfort also want to share these with their family. They even encourage their children and, to some extent, their parents, to pursue such pleasure and comfort. Younger interviewees particularly like to send parents material goods or services that bring pleasure, such as digital products or holidays. Those respondents thought of tourism as an ideal family activity. In addition to the personal pleasure gained from tourism, interviewees also think of it as a means to fulfil family commitments. Michael, a well-off manager around 40 years old, usually takes his wife and two children to places with beautiful natural views for holidays. He especially enjoys travelling with family, as 'it can bring more fun'. In a few similar cases, interviewees tend to emphasise the 'socialness' of taste in their interactions with family members and would like to reconcile their individual preferences with family cohesion. Bill, a 60-year-old retired director of a research institute, likes cultural heritage sites, while his wife and son prefer natural landscapes-so he compromises in order to share pleasures with his family. Here we can see the intersection between personal gratification and family commitment. As discussed by Warde and Martens (2000, 207), 'a key basis of gratification is social participation, particularly in situations where the enjoyment of each person is dependent upon the enjoyment of all, where affect or mood is irredeemably a joint creation'.

Self-referential orientation - the orientation toward personal pleasure and comfort-is thus significant in the taste of interviewees. The interviewees are generally keen on 
family commitments toward their children and parents, which can generate instrumental and social gratification; moreover, the purchase and use of material goods and services for family members aim mainly at fulfilling family commitments rather than the display of social status.

\section{The moral justification of taste}

It may be argued that the consumer orientation deemed 'legitimate' differs in traditional Western and Chinese cultures. The pursuit of pleasure and comfort is thought to be legitimate in Western culture, which has highlighted humanity and selfimprovement since the Enlightenment. Campbell (1987), through his work on modern hedonism, identifies the romantic ethic as the philosophical tradition that justifies the pursuit of novelty and pleasure. However, the Chinese culture has a different position on consumer orientation. The discourse of frugality has long dominated the history of Chinese society as a Confucianist or Taoist instrument for coherent social order-the former philosophy aims at a hierarchical social order, and the latter aims at the harmony between internal and external worlds (Fu 2000; Zhang 1999). In a tradition stressing unity between the individual and society, hedonism has not developed from Chinese culture. Therefore, Chinese people might need to introduce moral justifications in response to questions of whether the pursuit of personal interests can be legitimate in relation to the 'sociality' of the individual, together with aesthetic justifications regarding pleasure and comfort, to make themselves confident in their tastes. Of course, moral justifications are also important in the Western context (see Lamont (1992) and Woodward and Emmison (2001)). However, it is the balance between aesthetic and moral justifications, as well as how they were produced and how they work, that distinguishes Western and Chinese cultures.

The moral concerns of taste remain shallowly explored in existing scholarship (for an exception see Woodward and Emmison (2001)). The Chinese scholarship, which is keen on revealing the nature and the extent of consumerism, pays even less attention to the justification of taste. This paper reveals that 'affordability' (i.e. keeping a balance between expenditures and income) is an important form of moral justification. Almost all interviewees provide moral justifications of taste which are mainly concerned with 'affordability'. Sam and John are both considered extravagant by family and friends but can justify their tastes by referring to what they buy as 'affordable'. Sam, a 31-year-old real estate professional with a passion for investment, has bought two houses-one for his family and the other for his parents-and a car, which has left him with several bank loans. But he can afford to make his payments while maintaining his family's wellbeing. This particular taste can be justified in the aesthetic dimension by stimulation and instrumental gratification, derived from bringing a better life to his family and a sense of fulfilment. Besides, moral justification can also be found in his explanation of his taste:

I can afford the expenditure ... I think it's meaningless to save money for an emergency, as we are waiting for happiness not for accidents [laughs].

John, who often goes on luxury holidays, is also confident about his taste, as the expenses are not a burden to his family. 
When we plan to go, we don't have to save on other expenditures to pay for it and we go whenever we want (40, chief procurement officer for China division in a multinational company in chemicals).

The pursuit of pleasure and comfort is implied in their tastes. Furthermore, their moral justification mainly lies in the concern with finance: the pursuit of pleasure and comfort is balanced with a concern for income and for long-term welfare. Because 'affordability' plays such a crucial role in the justification of taste, a main source of anxiety is unable to afford what they would like. However, only two interviewees, both with relatively low income, show intense anxieties about their financial situation. There are also interviewees who formerly experienced, or are currently experiencing, ambivalence in their tastes: they are not sure if their tastes are good or bad. However, they account for only a small portion of the sample (three people) and are mainly people who take display of status or social identity as their main motive for consumption.

Therefore, the majority of the interviewees are satisfied and feel justified in their pursuit of pleasure and comfort. The high percentage of satisfaction among the interviewees should be understood in relation to their constrained material aspirations and practical financial strategies. Interviewees generally agree that a good taste is not always associated with expensive goods; consequently, satisfaction of their material aspirations does not necessarily lead to excessive expenditure. They also make efforts (e.g. through financial or real estate investment) to keep a balance between expenditure and income. This finding should also be understood with regard to the social context and characteristics of the middle class. The social status of the middle class has largely improved because of the reforms of 1978. Their higher cultural capital enables them to legitimate their pursuit of pleasure and comfort and their higher economic capital helps to keep their finances in balance, which the middle class uses to achieve moral justification.

A close examination of the Chinese middle class's justification of its tastes would provide us with some evidence of the contemporary change in social values. First, frugality, a traditional virtue, still has an impact on people's consumption. Yet, if it is economically affordable, the pursuit of pleasure and comfort is considered legitimate by the interviewees and not in need of justification on other moral grounds. Although the interviewees can obtain instrumental and social gratification through work achievement and sharing pleasure with family, hard work and sufficient family commitment are generally not considered necessary when pursuing pleasure and comfort. This paper does not deny the existence of conspicuous consumption but seeks to highlight self-referential orientations (i.e. the pursuit of personal pleasure and comfort) in the contemporary middle class and how these orientations are aligned in a distinctive way with the more traditional set of motives.

\section{Conclusion}

This paper has examined the justification of taste among members of the middle class in Beijing and their underlying consumer orientation. I argue that the pursuit of pleasure-the practice of seeking sensual, instrumental, contemplative and social pleasures-tempered by the pursuit of comfort, is a significant form of aesthetic justification; and that living within one's means, keeping a balance between expenditure and income, is the primary moral justification. The new set of motives among middle class consumers are conceptualised as the orientation toward personal pleasure and comfort, 
which introduces a set of justifiable practices-ones in which it becomes permissible to consider one's own pleasure and comfort when determining how to live one's life. On the one hand, the orientation toward personal pleasure and comfort, nonexistent in Maoist China, is implicit in consumer preferences and in the appropriation and appreciation of material goods among the middle class. On the other hand, consumer orientations nevertheless remain shaped by established social conventions, traditional values and social changes.

This paper seeks to examine how Chinese consumers justify their tastes. Aesthetic justifications imply a strong orientation toward personal pleasure and comfort, although there is a gender difference in seeking sensual and contemplative gratification. Interviewees also generally gain instrumental and social gratification from fulfilling family commitments, seeking pleasure not only through consumption for themselves but through purchasing material goods and services for family members. Furthermore, they encourage the pursuit of pleasure and comfort in their children and parents. Thus, the orientation toward personal pleasure and comfort in contemporary China has distinct features and operates in a different way from the consumerist orientation that originated and developed in the West. This is not to say, however, that Western consumers are indifferent to their children's and parents' welfare; rather, it should be understood in the way that the new consumer orientation in China has its distinct working mechanisms and cannot be considered as simply being imported or diffused from the West. Nevertheless, members of the middle class in Beijing no longer primarily justify their consumption through family commitments; instead, personal pleasure and comfort are as important as contributions to children and parents.

Although interviewees generally embrace pleasure and comfort, their consumption behaviour retains traditional features of frugality and moderation. The middle class contains well-disciplined people who consciously keep a balance between expenditure, income and long-term welfare. In offering justifications, some distinguish their consumption from commodity fetishism and vanity: it is not extravagant as long as it is affordable.

My findings challenge the stereotype of the Chinese 'new rich' and one-dimensional pictures of consumer culture in China. The middle class is diverse in consumption patterns across income, gender, age and other parameters. The degree of satisfaction and confidence with their consumption also varies. Interviewees emphasise self-referential orientations, implied in the pursuit of pleasure and comfort, but balance these against family commitments and maintaining a balance between income and expenditure. The consumption patterns of the 'new rich' must be understood in relation to their engagement in social practices and in social contexts. As the fieldwork was based in Beijing, not all the conclusions can be generalised to the middle class in the other metropolitan cities or to the whole of the middle class in China. Besides, consumption patterns in rural areas are distinct in many aspects, so the conclusions should be understood within an urban context. However, the sampling strategy ensures that the interviewees were selected from a wider population; hence, the conclusions can also be applied to other similar settings.

This study provides empirical evidence in support of justification of taste and the typology of gratification. It has shown that this conceptual apparatus and framework is useful for the study of consumer culture in the Chinese context. Justifications of taste 
help to reveal the consumer orientation, and the typology of gratification helps to clarify the orientation toward personal pleasure and comfort among the middle class. In the context of globalisation and social change, consumer orientation of the middle class implies the impact of global consumer culture and 'Western' culture-abundant consumer choices yield both autonomy and anxieties. However, this paper emphasises that the balance between various types of gratification in China differs from the West and the new set of consumer orientation is not the result of globalisation. The mechanism by which this consumer orientation was shaped will be explored in future research.

\section{Endnote}

${ }^{1 ' W e s t e r n ' ~ c u l t u r e ~ i s ~ u s e d ~ i n ~ t h i s ~ p a p e r ~ t o ~ i n d i c a t e ~ t h e ~ s e t ~ o f ~ p r o p o s i t i o n s ~ a n d ~ o r i e n t a-~}$ tions that are common and widespread in most developed capitalist economies, e.g. North America and Europe, but this does not mean that I take 'Western' culture to be homogeneous or one-dimensional. By the same token, 'Western countries/societies' or 'the West' are used to indicate the most developed capitalist countries, e.g. North America and Europe.

Competing interests

The author declares that she has no competing interests.

\section{Acknowledgements}

I would like to thank Professor Alan Warde and Dr Wendy Olsen, my PhD supervisors, for their great help and inspiring advice. I am also indebted to the interviewees who generously shared their time and stories with me.

Received: 21 December 2015 Accepted: 21 June 2016

Published online: 29 June 2016

\section{References}

Bourdieu, P. 1984. Distinction: a social critique of the judgement of taste. London: Routledge \& Kegan Paul. Campbell, C. 1987. The romantic ethic and the spirit of modern consumerism. Oxford: Basil Blackwell.

Campbell, C. 1995. In The sociology of consumption. Acknowledging consumption: a review of new studies, ed. D Miller, 96-126. London: Routledge.

Chen, X. 2003. Salvation or consumption: consumerism in the everyday life in China. Nanjing: Jiangsu People's Press.

Chua, BH. 2000. Consumption in Asia: lifestyles and identities. London, New York: Routledge.

Davis, DS. 2005. Urban consumer culture. The China Quarterly. 183:692-709.

Fu, YS. 2000. Removing luxury and keeping simplicity: tracing down the ancient point of view on consumption. Modern Finance and Economics 20(10):61-65.

Lamont, M. 1992. Money, morals, and manners: the culture of the french and american upper-middle class. Chicago: The University of Chicago Press.

Li, PL, and Y Zhang. 2008. Scale, identity and attitudes of the Chinese middle class. Society 28(2):1-20.

Liu, X. 2007. Class structure of urban China and definition of the middle class. Sociological Study 6:1-14.

Redding, SG. 1993. In the spirit of Chinese capitalism, ed. W. de Gruyter. Berlin, New York.

Scitovsky, T. 1976. The joyless economy: an inquiry into human satisfaction and consumer dissatisfaction. New York, London, Toronto: Oxford University Press.

Stewart, A, K Prandy, and RM Blackburn. 1980. Social stratification and occupations. London: Macmillan.

Tsai, SP. 2005. Impact of personal orientation on luxury-brand purchase value-an international investigation. International Journal of Market Research 47(4):429-454.

Wang, J. P. (2005, June 2010) "The consumer revolution: transitions in consumption patterns in urban China." from http://view.news.qq.com/a/20061120/000004.htm.

Wang, JP. 2006. Existence and bewilderment: tensions in consumption among the middle class in urban China. Academic Exchange 10:140-144.

Wang, N. 2007. The paradigm of the state transference: on the formation of consumerism in China. Journal of Sun Yatsen University (Social Science Edition) 47(4):1-7.

Wang, N. 2012. 'Symbolic stimulation' of consumer aspiration and 'structural constraint' of purchasing power: cause and consequences of consumption of urban residents in China). Social Sciences in Guangdong 3:196-208.

Warde, A. 2008. Dimensions of a social theory of taste. Journal of Cultural Economy 1(3):321-336.

Warde, A, and L Martens. 2000. Eating out: social differentiation, consumption and pleasure. Cambridge: Cambridge University Press.

Wong, NY, and AC Ahuvia. 1998. Personal taste and family face: luxury consumption in Confucian and western societies. Psychology \& Marketing 15(5):423-441.

Woodward, I. 2003. Divergent narratives in the imagining of the home amongst middle-class consumers: aesthetics, comfort and the symbolic boundaries of self and home. Journal of Sociology 39(4):391-412. 
Woodward, I, and M Emmison. 2001. From aesthetic principles to collective sentiments: the logics of everyday judgements of taste. Poetics 29:295-316.

Zhang, J. 1999. Review on the concept of consumption among the various schools in the Pre-Qin times. Journal of Shijiazhuang University of Economics 22(01): 73-78.

Zheng, HE. 2005. Consumerism in China and its development. Academic Forum 11:115-119.

Zhou, L. X. and M. K. Hui. 2003. Symbolic Value of Foreign Products in the People's Republic of China. Journal of International Marketing 11(2): 36-58.

Zhou, XH. 2005. Investigation of the Chinese middle class. Beijing: Social Science Academic Press.

Submit your manuscript to a SpringerOpen ${ }^{\circ}$ journal and benefit from:

- Convenient online submission

- Rigorous peer review

- Immediate publication on acceptance

- Open access: articles freely available online

- High visibility within the field

- Retaining the copyright to your article

Submit your next manuscript at $>$ springeropen.com 